
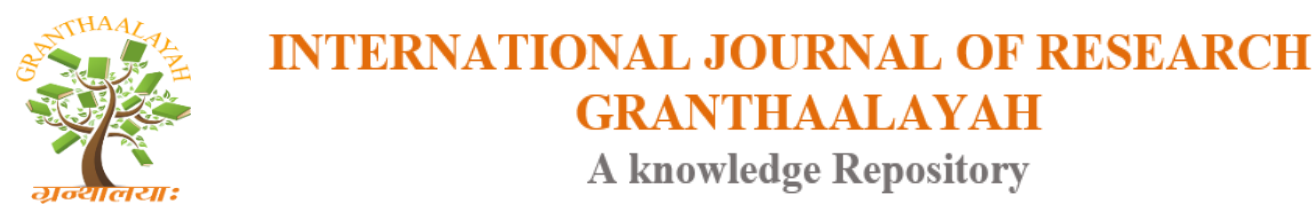

Management

\title{
TECHNOLOGICAL CRITICAL SUCCESS FACTOR IN ERP IMPLEMENTATION PROJECTS IN PUBLIC AND PRIVATE SECTOR IN SAUDI ARABIA
}

\author{
Mohamed Bekhet ${ }^{1}$, Saudah Sofian ${ }^{2}$ \\ ${ }^{1,2}$ Azman Hashim International Business School, Universiti Teknologi Malaysia, Skudai, Johor \\ Bahru, MALAYSIA
}

\begin{abstract}
An Enterprise Resource Planning (ERP) system implementation is a complex information technology project that integrates organization-wide operations. Prior surveys have reported perceptions about factors which are critical to ERP implementation success. There are only a few prior researches that have empirically tested the ERP implementation success factors in Saudi Arabia in both public and private organizations. This paper reports the result of literature review on critical success factor (CSF) for ERP implementations. It has been found that project champions can to be added to Technological dimension of the Technological, Organizational and Environmental (TOE) theory.
\end{abstract}

Keywords: ERP; CSF; Implementation Success; TOE.

Cite This Article: Mohamed Bekhet, and Saudah Sofian (2018). "TECHNOLOGICAL CRITICAL SUCCESS FACTOR IN ERP IMPLEMENTATION PROJECTS IN PUBLIC AND PRIVATE SECTOR IN SAUDI ARABIA.” International Journal of Research - Granthaalayah, 6(7), 306-316. https://doi.org/10.29121/granthaalayah.v6.i7.2018.1311.

\section{Introduction}

Private business organizations are digging deeper and deeper to find software solutions that can improve their performance, increase their competitive advantage, minimize costs and maximize their profit (Motwani et al., 2005). The same is true for public offices. Government organizations with their limited budget and other constraints have implemented different software applications that aim to increase their operational efficiency, improve organizational synergies, minimize costs and increase their return on investment. Government offices are expending huge amounts of money and investing on other valuable resources to implement different software applications that can be used for different functional or operational tasks (Raymond, Uwizeyemungu and Bergeron, 2005).

Xia et al. (2010) and Upadhyay and Dan (2008) define an ERP system as an information system consisting of software support modules where information is flowing between them and they share a central database. Some of these modules include utilities for marketing and sales, field service, 
product design and development, production and inventory control, procurement, distribution, industrial facilities management, process design and development, manufacturing, quality, human resources, finance and accounting, and information services. ERP combines business processes into one integrated solution. It is not just a software package but an efficient way of doing business Many ERP implementation projects achieve limited success and the failure rate is high i.e. between 60\% and 90\% (Xia et al., 2010; Al-Shamlan and Al-Mudimigh, 2011). Xia et al. (2010) also noted that usually the high failure rate of ERP implementation come from the difference in interests between customer organizations that aim to provide the optimum solutions for business problems and ERP vendors who prefer a generic solution applicable to a broader market. Also, many studies such as Jing and Qiu, (2007) and Al Shamlan and Al-Mudimigh (2011) indicated that the major reason for failure of ERP systems was the resistance of users to change or non-acceptance of new systems.

Business environment is becoming increasingly complex, making it difficult for firms to stay competitive (Haron et al., 2013). In this competitive environment, contingency factors are fast becoming a key instrument in business success. Recently management accounting research focuses on the contingency variable to help managers to make effective decisions because these variables have a significant influence on management accounting system and decision-making process (Gordon and Narayanan, 1984; Gul and Chia, 1994; Chapman, 1997; Gerdin and Greve, 2004).

The assumption of the contingency theory in management accounting is based on the belief that it is necessary to identify the relationship between contingency factors from external organization's environment, on the bases of accounting designs, approaches and techniques. Furthermore, the accounting information is beneficial for companies operating in competitive with long-term strategic tactics (Ismail and King, 2005). In this uncertain environment, the global economy is becoming increasingly uncertain, with rapid technological advances, constantly changing customer demands, increased deregulation and the dismantling of trade barriers (Mia and Clarke, 1999; Schulz, et al., 2010), these uncertain factors can significantly influence firm's chances of survival and success (Kaplan and Norton, 2001; Chenhall, 2003, Govindarajan, 1994). Therefore, the purpose of this study to find if there are new critical success factors affecting the implementation of ERP in SA for both public and private sectors. Since a number of Saudi companies have already implemented ERP, recommendations and guidelines gained from this research can be used to assist other companies in avoiding the potential problems associated with implementation.

The next section of this paper includes a review of previous research findings regarding ERP implementation. It presents an overview about Saudi Arabia as a country, ERP Adopters in it, and critical success factors (CSF) for ERP implementations. It also points out the related underlying theories. Based on the literature review, hypotheses and a conceptual framework developed.

\section{Saudi Arabia Country Review}

Located in western Asia and occupying most of the Arabian Peninsula Saudi Arabia with an area of 2,149,690 km2 is the second largest Arab country with a population of 31,567,173 (July 2015 estimate). Saudi Arabia is a member of the Gulf Cooperation Council GCC (Ochsenwald, Teitelbaum, \& Philby, 2016). Saudi Arabia's economy is an oil based one and it has around 16\% 
of the world's petroleum reserves and it is a major contributor in OPEC as the world's largest petroleum producers and exporters (Theodora, 2016).

\section{ERP Adopters in Saudi Arabia}

The Saudi ERP market is one of the biggest markets in the Middle East with Oracle and SAP as the key market players with their acquisition of the biggest market share (AlTurki, 2011) followed by other vendors' packages like Baan, Great Plains and Orion. Saudi ERP Adopters include different business sectors ranging from oil and gas, manufacturing companies, telecom operators, banking, utilities, government and others. Saudi Arabia E-Government services are expanding after the launch of the Yesser Program by the Ministry of Communication and Information Technology (MCIT) in partnership with the Ministry of Finance for promoting and implementing E-Government services. There are a number of governmental organizations that have started the adoption of ERP solutions with growing governmental investments in ERP systems in the upcoming years (Saudi Government, 2016).

\section{Defining Success of ERP Project Implementations}

The definition and measurement of success are thorny. Success depends on the point of view from which it is measured. People often meant different things when talking about ERP success. Project managers and ERP consultants often defined success in terms of completing the project plan on time and within budget. But people whose job was to adopt ERP system and use them tended to emphasize having a smooth operation with ERP system and achieving business improvements (Axline, Markus, Petrie, \& Tanis, 2001).

An important issue in the measurement of success is concerned when one measures it (Larsen \& Myers, 1997) because project managers and implementers can afford to declare success in the short run but executives and investors are in it for the long haul (Axline et al., 2001). To balance the judgment from project managers/consultants' perspective to customers/companies' perspective because we would like to be balance in our judgment by considering from both sides. It is also considered in our further empirical research that it is essential to investigate the CSFs from customers, consultants, and vendors' point of view.

Further, Axline (2001) argued that the companies that adopted ERP systems needed to be concerned with the success not just at the point of adoption, but also further down the road. Because our research involved project managers/implementer as well as the executives of the companies, we tend to look at the success from short run and long haul perspectives.

\section{Critical Success Factor (CSF)}

Critical success factors are those factors that the organization must do well to succeed while implementing ERP projects. In relation to the CSF, implementation factors (IFs) are the important aspects of ERP implementation process which affect the outcome of the project (Leidecker and Bruno, 1984). Previous studies indicate importance of CSFs to ensure success of their ERP system implementations. For example Cameron and Meyer (1998) investigate ERP system deployments failure and success. Their study suggests that CSFs can make or break implementations. 
Karakanian (1999) suggests that CSFs are an integral part of a firm's successful ERP system deployment strategy. Bingi et al. (1999) emphasizes the importance of firms using a balanced mix of organizational and technical CSFs for ensuring successful ERP system implementations. Lall (2003) and Satyan (2003) indicate that firms emphasize appropriate CSFs for their holistic implementations as their focus shifted to operational and usage rather than deployment issues. AlMashari et al. (2003) attempt to tie CSFs to implementation time and improved performance benefits, their study's findings suggest that those firms which effectively manage their CSFs can shorten their implementation time and garner substantial early benefits from their ERP systems. Further, the benefits of ERP system deployment are maximized when CSFs are leveraged to facilitate the relationship between ERP system implementation and changes in business performance (Madapusi 2008).

\section{Theoretical Framework}

In order to investigate the relationships drawn between CSFs and ERP implementation success, this study benefits from two underlying theoretical foundations including life cycle theory (LCT) and TOE theory. In this section, these definitions are briefly explained, and the relationships related to these theories are discussed further.

\subsection{The Technological, Organizational and Environmental (TOE) Theory}

Technological factor in TOE theory considers the importance of technological insight in both internal and external perspective also useful in promoting organizational output (Tornatzky et al., 1990). These technologies contain various phases of the information system (IS), from foundation capabilities to the compatibility related to the organization. These technical characteristics will ease the foundation for the realization of benefits for the organization.

Technological factors are introduced as a powerful predictor in the pre-implementation or implementation ERP (Chwelos et al., 2001; Zhu and Kraemer, 2005).

Organizational factors are the resources existing to support and maintain the acceptance and success of the system.

These factors include company managerial structure and size, as well as delicate characteristics of the organization i.e., organizational readiness to support the arrangement and a well atmosphere to use system such as ERP (Tornatzky et al., 1990; Chau and Tam, 1997).

Organizations have to prepare an optimistic circumstance for the system to implement effectively; hence organizational activities are vital for the ERP to promote businesses. The environmental factors involve that the organizations external environment could influence the implementation process of the system through the central organization. Because implementing ERP within the entire organization is a complex function, the operation process of ERP requires in-depth information the ERP implemented organization may not have i.e., knowledge. By the way, organizations are influenced by their related industries, its competitors, and the ability of the firms to obtain the resources supplied by others. 


\subsection{Theoretical Foundation of Life Cycle (LCT) Theory}

The life cycle theory presents the main approach in this study on the implementation process. Life cycle theory posits that both the perceived attributes of the innovation and the firm's characteristics (mainly centralization, size, slack, formalization, and interconnectedness) influence the implementation and use of an innovation (Tornatzky and Feleischer, 1990; Rogers, 1995). For instance, Tornatzky and Feleischer's (1990) model considers three aspects of the firm's factor that influence a complex innovation's as pre-implementation, implementation and implementation process.

The three groups of factors, also denoted as TOE, are technological, organizational, and environmental. The additional environment category is an important component in the model, as it could present both constraints and opportunities to its operations (Tornatzky and Feleischer, 1990). The firm's environment includes its industry, its partners and competitors, external resources, the government, and any other direct or indirect source of pressures or motivations that could affect its operations.

The organizational factor describes measures such as the quality of its human resources, the size and scope, the degree of centralization and formalization, and the amount of slack resources. The technological factor considers the internal and external technological resources that are available to the firm. The TOE has been used in several studies to examine the pre-implementation and implementation of several information system (IS) applications, including technologies proven to be empirically appropriate and useful for studying complex innovations (Zhu et al., 2004). Therefore, there is a need to more researches to stress the relevance of contingency factors (including organizational, technological, and external factors) for ERP implementation and benefits realization (Kouki et al., 2007, 2010; Zhu et al., 2010).

\section{Conceptual Framework}

Based TOE theory and contributions of Kouki et al. (2007, 2010), Zhu et al. (2010) and Kish (2016) a Conceptual Framework is developed and it is divided into two major parts: Dependent variables which is ERP success and independent variable which defines Technological CSF as shown in Figure 1.

\subsection{Technological CSF}

\section{- ERP Attributes}

ERP attributes is defined as ease of use, relative advantage, and compatibility of ERP, which are more influential during the early implementation phase when users are learning about the system (Wu and Wang, 2006; Hsieh and Wang, 2007; Amoako-Gyampah, 2007). Moore and Benbasat (1991) proposed that relative advantage, compatibility, ease of use etc. influence the technological issues in implementation phase. In other study, Somers et al. (2004) used ERP attributes to measure performance by items i.e., content, accuracy, timeliness, and ease of use. Similarly, Wu and Wang (2006) suggested ease of use and usefulness of the system for the user as the key factor in assessing performance. Therefore, hypothesis 1 is proposed: 
Hypothesis 1: Organizations that develop a strategic basis for implementing ERP systems have a greater chance of success than organizations that implement do not.

\section{- ERP Internal Expertise}

ERP internal expertise is defined as internal capabilities to support operators and managers to troubleshooting the system, by providing the necessary maintenance, refinement, and adaptation. Managers i.e., IT managers, chief executive officers (CEO) possibly will not have an accurate impression about the requirement of the ERP, its capabilities and how to trouble shooting the ERP.

Therefore, there is a need to internal experts to better understanding these issues. Mostly ERP vendors deny the responsibility for hardware and internal network problem, so the internal ERP memories experts have the essential knowledge to provide a reliable support (Grossman and Walsh, 2004). Furthermore, when the ERP is adopted and run all throughout the organization, the $1 \mathrm{~T}$ department would be in charge for debugging and troubleshooting the ERP, continuously purifying and adjusting it in line with business needs and users (Stratman and Roth, 2002; Kumar et al., 2003). Hypothesis 2 is then suggested: Hypothesis 2: Organizations that identify their weaknesses and increase their staff' ERP consultants expertise have a greater chance of success than those that do not.

\section{- ERP Configuration}

ERP configuration refers to well structure and configuration of ERP programs through the organization (Karimi et al., 2007; Zhu et al., 2010). A proper ERP configuration is cooperative in order to offer optimized and effective package of the ERP, which can easily integrate into the organization (Nah et al., 2003). Quite the opposite, an unclear ERP configuration might increase the potential crises of weak and non-effective function of the ERP.

Furthermore, a proper system configuration prepares a worthy tutorial version of the ERP before the organization wide ERP program perform all throughout the organization (AlMashari et al., 2003). Due to the impediment of the ERP, there are numerous bugs and problems in the implemented ERP, which might cause collapses of the ERP during its routine and daily process.

A well ERP configuration simplifies the detection of these problems ahead and accurate them in the consistent routine operation. Therefore, ERP configuration can improve the possibilities in attaining the operational and managerial benefits. The above discussion leads to hypothesis 3 :

Hypothesis 3: An accurate ERP configuration increases the chances of getting benefits from an ERP project

\section{- Project management}

Perhaps the single most decisive element of ERP success or failure is the knowledge, skills, abilities, and experience of the project manager (Wade \& Hulland, 2004). Project manager is the one who is coordinating, scheduling and monitoring the predefined activities to ensure that the stated objectives of the projects are achieved (Weill \& Vitale, 2002). 
An ERP project manager must understand both the business and the technology. An ERP project manager must understand the impact of the ERP implementation on the business, and work with business managers to ensure a smooth transition from the "as is" to the "to be" business operating environment. For this a project manager is one who is flexible, disciplined, quick learner, a good decision maker, experienced in ERP implementation, business experience, political clout, good communication and can motivate project participants. Therefore, the following hypothesis is suggested:

Hypothesis 4: A full time qualified project manager increases the chances of an ERP projects success

\section{- ERP Communication}

Communication throughout the firm and among all organizational levels, within the ERP life cycle is vital to assure implementation success of ERP (Madapusi, 2008). According to Al-Mashari et al. (2003) and Tarafdar and Roy (2003), communication and coordination with different stakeholders of ERP life cycle is crucial for achievement of ERP success. An open information policy provokes better realization of organizational needs leading to effective application of the ERP. Harvesting from the above, hypothesis is developed:

Hypothesis 5: A proper communication plan defined from the beginning of the project increases the changes of an ERP projects success.

Based on the Somers and Nelson (2001), Bhagwani (2009), Aaldammas, A. and A.S. ALMudimigh (2011), Ngai, Law and Wat (2008). Law and Ngai (2007), Motwani, Subramanian, and Gopalakrishna (2005), He (2007) and Lam, (2005) a new factor is proposed to be added to the TOE theory which is Project Champions as the champion has in-depth knowledge and sound experience in the operation of the organization, lead and effectively communicate the benefits of ERP to end users, as well as the project team members (Somers \& Nelson, 2001)

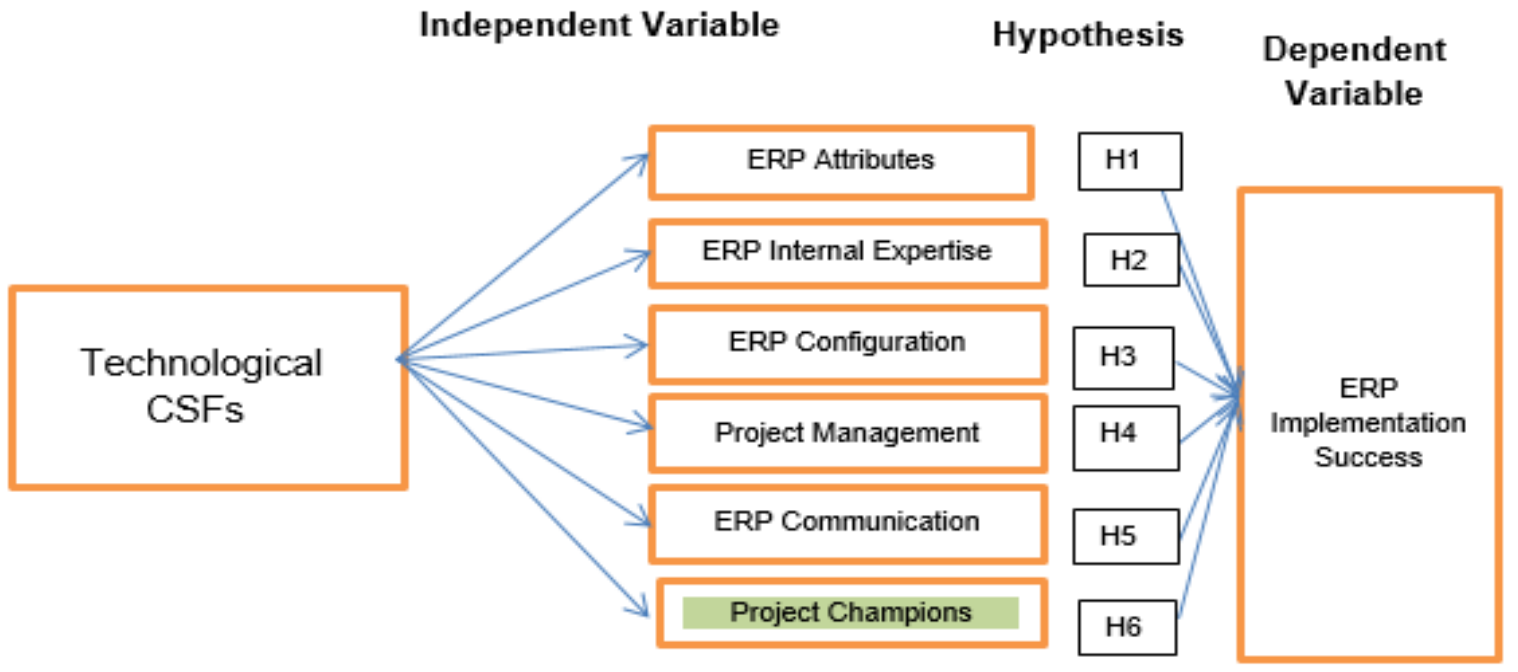

Figure 1: Proposed Conceptual Framework

Source: Adopted and extended from Kouki et al. (2007, 2010), Zhu et al. (2010) and Ehsan Kish (2016) 


\section{Methodology to Validation of Conceptual Model}

This paper provides a conceptual model for both scholars and professionals that represent Technological CSFs through applying the TOE framework to ERP implementation success. Moreover, this paper adds to the body of knowledge by improving a conceptual model with strong supported by theory that contains an assortment of CSFs that some of their relationship with ERP implementation success under the support of TOE have not been empirically validated yet. In particular, this paper serves to prepare researchers approaching the critical factors that have not been examined in past studies, especially ERP Project Champion. This paper only completes a primary level by preparing an optimum theoretical validated model for optimization CSFs of ERP implementation success and examines these relationships assigned. Following the methodology successfully used in previous related papers (e.g., Gunasekaran and Ngai, 2005; Van der Vaart and van Donk, 2008), this study reviews prior research publications. The logic of established relationship between variables in the conceptual framework be elaborated by discussing characteristics of proposed model with other previous ERP implementation success literatures. Further analysis, justifications and supporting literature about theoretical underpinning of Project Champion as one of CSF in the proposed model has been discussed. After comprehensive discussion of each characteristic, the proposed model of this study is presented in Figure 1.

\section{Conclusion and Recommendation}

The study contributes to the TOE theory by adding proposed new technological CSF, Project champion. The proposed research framework in this paper has not yet empirically examined. Further researches in the future to examine TOE theory and try to contribute to the theory may be conducted by adding new factors to both organizational and environmental factors. The researchers hope that other scholars will integrate these ideas to promote knowledge of ERP implementation.

\section{References}

[1] Abdelghaffar, H. (2012), "Success factors for implementation in large organisations: the case of Egypt", The Electronic Journal on Information Systems in Developing Countries, Vol. 52 No. 4, pp. 1-13.

[2] Adamson, I. and Shine, J. (2003), "Extending the new technology acceptance model to measure the end user information systems satisfaction in a mandatory environment: a bank's treasury", Technology Analysis and Strategic Management, Vol. 15 No. 4, pp. 441-455.

[3] Agarwal, R. (2000), "Individual acceptance of new information technologies", in Zmud, R.W. (Ed.), Framing the Domains of IT Management Research: Glimpsing the Future through the Past, Pinnaflex, Cincinnati, $\mathrm{OH}$.

[4] Agourram, H. (2009), "The quest for information systems success in Saudi Arabia: a case study", Journal Global Management Research, pp. 51-57, available at: http://gmrjournal.uqam.ca/documents/GMRJ-V5N1-JUN2009-77-91.pdf\#page=50

[5] Al-Gahtani, S.S. (2003), "Computer technology adoption in Saudi Arabia: correlates of perceived innovation attributes", Information Technology for Development, Vol. 10 No. 1, pp. 57-69.

[6] Al-Gahtani, S.S. (2004), "Computer technology acceptance success factors in Saudi Arabia: an exploratory study”, Journal of Global Information Technology Management, Vol. 7 No. 1, pp. 5 5-29.

[7] Al-Gahtani, S.S., Hubona, G.S. and Wang, J. (2007), "Information technology (IT) in Saudi Arabia: culture and the acceptance use of IT”, Information \& Management, Vol. 44 No. 8, pp. 681-691. 
[8] Al-Jabri, I.M. and Al-Hadab, A. (2008), "End user adoption of ERP systems: investigation of four beliefs", Americas Conference on Information Systems (AMCIS), pp. 1-8.

[9] Al-Jabri, I.M. and Roztocki, N. (2010), "Adoption and use of information technology in mandatory settings: preliminary Insights from Saudi Arabia", Proceedings of the Sixteenth Americas Conference on Information Systems, Lima, pp. 1-7.

[10] Al-Mashari, M., Ghani, S.K. and Rashid, W. (2006), "A Study of the critical success factors of ERP implementation in developing countries", International Journal of Internet and Enterprise Management, Vol. 4 No. 1, pp. 68-95.

[11] Al-Shamlan, H. M., \& Al-Mudimigh, A. S. (2011). The Chang Management Strategies and Processes for Successful ERP Implementation: A Case Study of MADAR. International Journal of Computer Science, 8, 431-435.

[12] Al-Turki, U.M. (2011), "An exploratory study of ERP implementation in Saudi Arabia", Production Planning \& Control, Vol. 22 No. 4, pp. 403-413.

[13] Aladwani, A.M. (2001), "Change management strategies for successful ERP implementation", Business Management Journal, Vol. 7 No. 3, pp. 266-275.

[14] Alballaa, H. and Al-Mudimigh, A. (2011), "Change management strategies for effective enterprise resource planning systems: a case study of a Saudi company", International Journal of Computer Applications, Vol. 17 No. 2, pp. 14-19.

[15] Aldammas, A. and Al-Mudimigh, A.S. (2011), "Critical success and failure factors of implementations: two case studies from Kingdom of Saudi Arabia", Journal of Theoretical and Applied Information Technology, Vol. 28 No. 2, pp. 73-82.

[16] Allen, D., Kern, T. \& Havenhand, M. (2002). ERP critical success factors: An exploration of the contextual factors in public sector institutions. Proceedings of the 35th Hawaii International Conference on System Sciences. Retrieved November 12, 2006 from http://csdl2.computer.org/comp/proceedings/hicss/2002/1435/08/14350227.pdf.

[17] Amoako-Gyampah, K. and Salam, A.F. (2004), "An extension of the technology acceptance model in an ERP implementation environment”, Information \& Management, Vol. 41 No. 6, pp. 731-745.

[18] Asmamaw A. Mengistie (2012) Analysis of the Critical Success Factors for ERP Systems Implementation in U.S. Federal Offices), Retrieved May 15, 2016, from http://link.springer.com/chapter/10.1007/978-3-642-37021-2_15

[19] Axline, S., Markus, M. L., Petrie, D., \& Tanis, C. (2001). Learning from experiences with ERP: problems encountered and success achieved. In Shanks G., Seddon P. B., \& Willcocks L. P. (Eds.), Second-wave enterprise resource planning systems (p. 23-54). Edinburgh: Cambridge University Press.

[20] Bagozzi, R.P. (2007), "The legacy of the technology acceptance model and a proposal for a paradigm shift", Journal of the Association for Information Systems, Vol. 8 No. 4, pp. 243-254.

[21] Baker, E.W., Al-Gahtani, S.S. and Hubona, G.S. (2007), "The effect of gender and age on new technology implementation in a developing country: testing the theory of planned behavior (TPB)", Information Technology \& People, Vol. 20 No. 4, pp. 352-375.

[22] Baker, E.W., Al-Gahtani, S.S. and Hubona, G.S. (2010), "Cultural impacts on acceptance and adoption of information technology in a developing country", Journal of Global Information Management, Vol. 18 No. 4, pp. 35-58.

[23] Bandyopadhyay, K. and Rarnes, C. (2012), "An analysis of factors affecting user acceptance of ERP systems in th United States", International Journal of Human Captial and Information Technology Professionals, Vol. 3 No. 1, pp. 1-14.

[24] Bano, M. and Zowghi, D. (2013), "User involvement in software development and system success: a systematic literature review", Proceedings of the 17th International Conference on Evaluation and Assessment in Software Engineering, ACM, Porto de Galinhas, pp. 125-130.

[25] Barbosa, D.H. and Musetti, M.H. (2010), "Logistics information systems adoption: empirical investigation in Brazil”, Industrial Management \& Data Systems, Vol. 110 No. 6, pp. 787-804. 
[26] Barki, H. and Hartwick, J. (1994), "Measuring user participation, user involvement, and user attitude”, MIS Quarterly, Vol. 18 No. 1, pp. 59-82.

[27] Bentler, P.M. (1990), "Comparative fit indexes in structural models", Psychological Bulletin, Vol. 107 No. 2, pp. 238-246.

[28] Brehm, L. \& Markus, M.L. (2000, June 11-13). The divided software life cycle of ERP packages. Proceedings of the 1st Global Information Technology Management (GITM) World Conference, 43-46. Memphis, TN.

[29] Browne, M.W. and Cudeck, R. (1992), "Alternative ways of assessing model fit", Sociological Methods \& Research, Vol. 21 No. 2, pp. 230-258.

[30] Bueno, S. and Salmeron, J.L. (2008), "TAM-based success modeling in ERP”, Interacting with Computers, Vol. 20 No. 6, pp. 515-523.

[31] Burton-Jones, A. and Hubona, G.S. (2005), "Individual differences and usage behavior: revisiting a technology acceptance model assumption", SIGMIS Database, Vol. 36 No. 2, pp. 58-77.

[32] Byrne, B. (2010), Structural Equation Modeling with AMOS, Taylor and Francis Group, LLC,New York, NY.

[33] Chang, M.-K., Cheung, W., Cheng, C.-H. and Yeung, J.H.Y. (2008), "Understanding ERP system adoption from the user's perspective", International Journal of Production Economics, Vol. 113 No. 2, pp. 928-942.

[34] Chen, F.F., Sousa, K.H. and West, S.G. (2005), “Teacher's corner: testing measurement invariance of second-order factor models", Structural Equation Modeling, Vol. 12 No. 3, pp. 471-492.

[35] Crowley, A. (1998, Dec 14). Training treadmill. PC Week, 15, 121.

[36] Cui, G. and Liu, K. (2010), "Organizational readiness analysis for enterprise information systems implementation", Journal of Software, Vol. 5 No. 5, pp. 554-561.

[37] Daniel, D. (1997, October 27). PeopleSoft and SAP square off in two-horse race. Computing Canada, 23, 38.

[38] Davenport, T.H. (1998), "Putting the enterprise into the enterprise system", Harvard Business Review, Vol. 75 No. 4, pp. 121-131.

[39] Davis, F.D. (1989), "Perceived usefulness, perceived ease of use, and user acceptance of information technology", MIS Quarterly, Vol. 13 No. 3, pp. 319-340.

[40] Davison, R. (2002), "Cultural complication of ERP: valuable lessons learned from implementation experiences in parts of the world with different cultural heritages", Communication of the ACM, Vol. 45 No. 7, pp. 109-111.

[41] De Lone, W. H., \& McLean, E. R. (1992). Information systems success: the quest for the dependent variable. Information Systems Research, 3(1), 60-95.

[42] Deloitte Research. (2002). The keys to smart enterprise transformation for the public sector Deloitte Consulting and Deloitte \& Touche. Retrieved April 5, 2011, from http://www.deloitte.com/dtt/cda/don/content/keys\%20to\%20Smart\%20ET.pdf

[43] Deloitte Research. (2005). ERP change management survey Retrieved May 26, 2011, from http://www.deloitte.com/assets/Dcom-

UnitedStates/Local\%20Assets/Documents/us_cnsltg_hc_shrmerp_040106.pdf.

[44] Dezdar, S. and Ainin, S. (2011), "The influence of organizational factors on successful ERP implementation", Management Decision, Vol. 49 No. 6, pp. 911-926.

[45] Doll, W.J. and Torkzadeh, G. (1989), "A discrepancy model of end-user computing involvement", Management Science, Vol. 35 No. 10, pp. 1151-1171.

[46] Esteves, J. \& Pastor, J. (2000). Towards the unification of critical factors for ERP implementations.10th Annual Business Information Technology (BIT) 2000 Conference. Manchester:

[47] Esteves, J. \& Pastor, J. (2002). A framework to analyze most critical work packages in ERP implementation projects. International Conference on Enterprise Information Systems. Spain.

[48] Everdingen, Y.M.v. and Waarts, E. (2003), "The effect of national culture on the adoption of innovations", Marketing Letters, Vol. 14 No. 3, p. 217. 
[49] Garg, P. (2010), "Critical failure factors for enterprise resource planning implementations in Indian retail organizations: an exploratory study", Journal of Information Technology Impact, Vol. 10 No. 1, pp. 35-44.

[50] Gibson, N., Holland, P., \& Light, B. (1999). A critical success factors model for enterprise resource planning implementation. Proceedings of the 7th European Conference on Information System, Vol 1, 273-297.

[51] Graig, S. (2000, April 3). ERP vendors admit they can't do it all; some are reselling other vendors' apps. Computer World, 2.

[52] Gurley, W. (1999, May). The new market for rentalware': Beyond ERP systems. Fortune, 139,142

[53] Haddara, M. and Zach, O. (2011), "ERP systems in SMEs: a literature review", 44th Hawaii International Conference on System Sciences (HICSS), IEEE, pp. 1-10.”

[54] Hall, E.T. (1976), Beyond culture, Anchor, New York, NY.

[55] Hartwick, J. and Barki, H. (1994), "Explaining the role of user participation in information system use", Management Science, Vol. 40 No. 4, pp. 440-465.

[56] Hawari, A.a. and Heeks, R. (2010), "Explaining ERP failure in a developing country: a Jordanian case study", Journal of Enterprise Information Management, Vol. 23 No. 2, pp. 135-160.

[57] "Heydenrych, G. \& Cloete, E. (2007). ERP transition to e-commerce: Training for a new methodology. Proceedings of the 2007 Computer Science and IT Education Conference. (p. 323334)."

[58] Hofstede (1991), Cultures and Organizations: Software of the Mind, McGraw-Hill, Madenhead.

[59] Hofstede (2001a), Culture's Consequences: Comparing Values, Behaviors, Institutions, and Organizations Across Nations, Sage Publications Inc., Thousand Oaks, CA.

[60] Hofstede, G. (1980), Culture's Consequences: International Differences in Work Related Values, Sage, Beverly Hill, CA.

[61] Hofstede, G. (2001b), Culture's Consequences: Comparing Values, Behaviours, Institutions and Organisations Across Nations, Sage Publications, London.

[62] Hofstede, G. and Bond, M.H. (1988), "The Confucius connection: from cultural roots to economic growth", Organizational dynamics, Vol. 16 No. 4, pp. 4-21.

[63] Holsapple, C.W., Wang, Y.M. and Wu, J.H. (2005), "Empirically testing user characteristics and fitness factors in enterprise resource planning success", International Journal of Human-Computer Interaction, Vol. 19 No. 3, pp. 323-342.

*Corresponding author.

E-mail address: mbfoda@ hotmail.com 